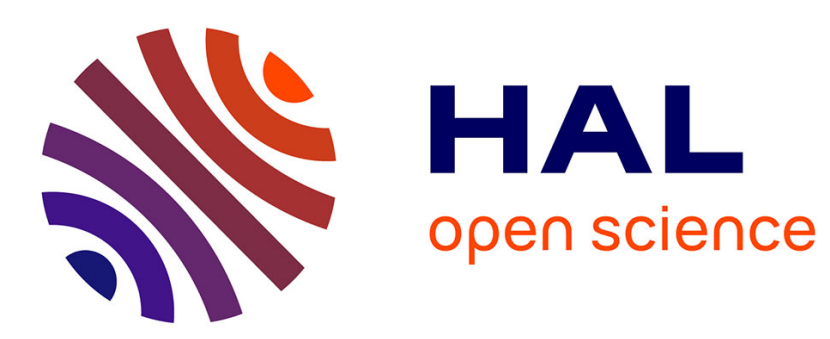

\title{
Inflation, Volatile Public Spending, and Endogenously Sustained Growth
}

\author{
Dimitrios Varvarigos
}

\section{To cite this version:}

Dimitrios Varvarigos. Inflation, Volatile Public Spending, and Endogenously Sustained Growth. Journal of Economic Dynamics and Control, 2010, 34 (10), pp.1893. 10.1016/j.jedc.2010.05.014 . hal00732760

\section{HAL Id: hal-00732760 \\ https://hal.science/hal-00732760}

Submitted on 17 Sep 2012

HAL is a multi-disciplinary open access archive for the deposit and dissemination of scientific research documents, whether they are published or not. The documents may come from teaching and research institutions in France or abroad, or from public or private research centers.
L'archive ouverte pluridisciplinaire HAL, est destinée au dépôt et à la diffusion de documents scientifiques de niveau recherche, publiés ou non, émanant des établissements d'enseignement et de recherche français ou étrangers, des laboratoires publics ou privés. 


\section{Author's Accepted Manuscript}

Inflation, Volatile Public Spending, and Endogenously Sustained Growth

Dimitrios Varvarigos

PII: $\quad$ S0165-1889(10)00125-9

DOI: doi:10.1016/j.jedc.2010.05.014

Reference: DYNCON2425

To appear in: $\quad$ Journal of Economic Dynamics

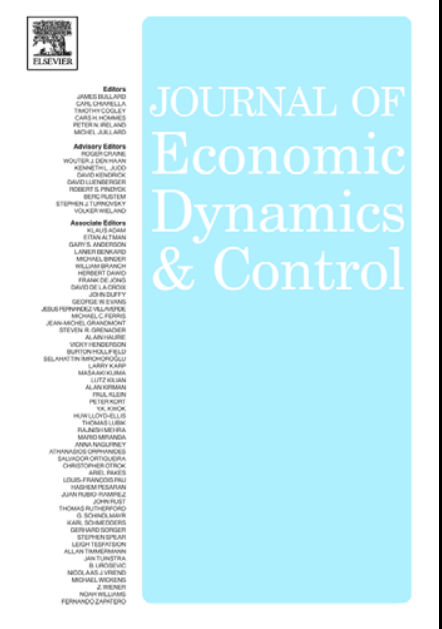

www.elsevier.com/locate/jedc \& Control

Received date: 11 June 2008

Accepted date: 3 March 2010

Cite this article as: Dimitrios Varvarigos, Inflation, Volatile Public Spending, and Endogenously Sustained Growth, Journal of Economic Dynamics \& Control, doi:10.1016/j.jedc.2010.05.014

This is a PDF file of an unedited manuscript that has been accepted for publication. As a service to our customers we are providing this early version of the manuscript. The manuscript will undergo copyediting, typesetting, and review of the resulting galley proof before it is published in its final citable form. Please note that during the production process errors may be discovered which could affect the content, and all legal disclaimers that apply to the journal pertain. 


\title{
Inflation, Volatile Public Spending, and Endogenously Sustained Growth
}

\author{
Dimitrios Varvarigos ${ }^{\ddagger}$ \\ University of Leicester
}

\begin{abstract}
I construct a model of an economy whose government finances volatile public spending via money creation. The model jointly accounts for the emergence of some well-known empirical observations. Specifically, it predicts a negative correlation between output growth and policy volatility. Furthermore, given that both the mean and the variance of the inflation rate are elevated by fluctuations in public spending, the model provides a novel theoretical justification for the simultaneous negative correlation of long-run growth with both average inflation and inflation variability. The model also supports the view that policy volatility reduces social welfare.
\end{abstract}

JEL classification: E13; E31; O42

Keywords: Growth; Inflation; Seignorage; Volatility

\footnotetext{
‡ Address: Department of Economics, Astley Clarke Building, University Road, Leicester LE1 7RH, England. Telephone: ++44 (0) 1162522184 Email: $\underline{\text { dv33@le.ac.uk }}$
} 


\section{Introduction}

In many developing economies, government policies like public spending display a certain degree of volatility. The following Table is suggestive as it shows that, in various SubSaharan African countries, the government's share on GDP per capita is far from being (even roughly) constant. ${ }^{1}$ Instead, we can observe significant variations for this indicator of the public sector's involvement in the economy. For example, in Zimbabwe the standard deviation of the government's share is $4.78 \%$, with an average of $9.52 \%$, while for Zambia the corresponding values are $5.71 \%$ and $15.86 \%$ respectively. Thus, it appears that the extent of variation in government activity is a particularly pertinent issue for developing economies.

\section{[INSERT TABLE 1 HERE]}

The incidence of policy volatility may reflect either an inherently unstable political environment or policy mismanagement and mistakes or even governance challenges that may result in the deviation of policies from their optimal path. A significant outcome emerges with the possibility that variability in policies can provide an additional factor determining the long-term macroeconomic performance, as this is appropriately reflected by the trend of output growth. This has been an issue of concern for both empirical (e.g., Brunetti, 1998; Fatás and Mihov, 2005; Furceri, 2007) and theoretical analyses (e.g., Aizenman and Marion, 1993; Hopenhayn and Muniaguria, 1996; Varvarigos, 2007). While the latter derive theoretical results that seem to be rather mixed, the existing empirical studies reach a consensus on a negative correlation between various measures of policy volatility and average GDP growth. ${ }^{2}$ The importance of such results is readily understood once we realise that even small changes in trend growth - if sustained - are sufficient to generate substantial changes to the level of real GDP (and the standards of living) over the medium- and long-term.

\footnotetext{
1 The data was retrieved from Heston, A., Summers, R., Aten, B., 2009, Penn World Table version 6.3, Centre for International Comparisons of Production, Income and Prices, University of Pennsylvania. It can be accessed online via http://pwt.econ.upenn.edu/php site/pwt63/pwt63 form.php.

${ }^{2}$ Fatás and Mihov (2005) find that policy volatility is the key characteristic in the relationship between government policies and economic growth. For this reason, they claim that volatility is a better qualitative indicator of economic policy compared to other instruments such as the level of such policy or the quality of institutions.
} 
Existing theoretical studies consider cases where the volatility of government policies is absorbed and - partially or completely - transmitted to the macroeconomic environment via fiscal instruments such as proportional tax rates and subsidies. Many economists, however, suggest that seignorage (that is, the revenues a government can generate by increasing the money supply) is a more suitable financing instrument for temporary variations in public spending. ${ }^{3}$ Support for this view is provided by Click (1998) who reports estimation results showing a statistically significant correlation between measures of seignorage and the standard deviation of government spending for a cross-section of countries, and by Loayza et al. (2007) who suggest that "governments often instigate macroeconomic volatility by conducting erratic fiscal policy and, even worse, by financing it at times through similarly volatile inflationary monetary policy" (Loayza et al., 2007; page 347). In addition to the relative ease and speed of money creation, as opposed to the more lengthy political and legislative procedure required to adjust various forms of taxation, there are other commonly accepted arguments that render seignorage an appealing financing instrument to governments of many developing economies. These relate to the insufficient revenues from taxation (due to the low tax base, the imperfect tax collection mechanisms and widespread tax evasion), the poor credit ratings that prevent some developing countries from borrowing in world financial markets and the political benefits derived from the fact that the electorate is generally averse to direct taxation and inclined to 'punish' those who impose it. Indeed, existing evidence (Click, 1998; Koreshkova, 2006) illustrates that, for a large number of developing countries, revenues from money creation account for a significant fraction of total government revenues, while Basu (2001) reports the results of a cross-country study that indicates a positive and statistically significant correlation between the average seignorage rate and the public investment rate. The significance of inflationary finance for developing countries is even more aptly reflected in an idea brought forward by Agbonyitor (1998): he argues that structural economic reforms in several Sub-Saharan African countries were undermined by reductions in the provision of public services and poor maintenance of public infrastructure as a result of shortages in local funds due to reduced seignorage.

Despite all these arguments and evidence, the idea of combining policy volatility and inflationary finance in a theoretical model of growth has eluded the attention of researchers. In this paper I seek to fill this gap: I construct a model whereby the accumulation of

\footnotetext{
${ }^{3}$ See Fischer (1982) and Poterba and Rotemberg (1990) among others.
} 
(intangible) human or efficiency capital provides the source of endogenous productivity improvements and, therefore, sustained growth. Within this context I assume that the government provides a stream of public spending - financed via money creation - whose important feature is that it fluctuates overtime. The growth rate of money supply becomes a function of public spending - more importantly, a non-linear one - because money represents an instrument of public finance. Thus, the key to my analysis is that the stochastic process for money supply is not independent but rather driven by the stochastic process of the public spending variable.

This crucial feature is what generates the model's basic results. In equilibrium, an increase in policy volatility accounts for a simultaneous boost in both the inflation rate and its variance. Thus, although the increase in the variance of money supply contributes - by itself - to higher growth, the simultaneous increase in the inflation rate impedes the growth rate of output. The latter effect dominates and the incidence of volatility provides a detrimental factor for the growth prospects of the economy. These mechanisms are particularly important because they are able to reconcile the results from existing neoclassical growth models - in which nominal volatility actually appears to stimulate growth (Dotsey and Sarte, 2000) - with strong empirical evidence (e.g., Grier and Tullock, 1989; Judson and Orphanides, 1999; Grier and Perry, 2000; Fountas and Karanasos, 2007) which shows that both inflation and its variance display a significant, negative correlation with GDP growth. The argument of my analysis is that, to a large extent, policy volatility is the link that connects and correlates the important measures of macroeconomic performance. This is because more volatile policies are responsible for lower output growth, higher average inflation and higher inflation volatility simultaneously. ${ }^{4}$

The rest of the paper is organised as follows: Section 2 outlines the fundamental characteristics of the model economy. In Section 3, I define and derive the dynamic general equilibrium and in Section 4, I analyse the effect of public spending volatility on long-run growth. Section 5 identifies how the impact of policy volatility on human capital accumulation is channelled through the effects of public spending on average money growth and its variability, shows the correlations between average inflation, inflation volatility and

\footnotetext{
${ }^{4}$ In this respect, the model formalises an argument brought forward by Friedman (1977): he explicitly referred to various public policies (other than monetary policy) as responsible for the observation that high (on average) inflation tends to be more volatile as well.
} 
trend growth, and analyses the corresponding welfare effects. Section 6 discusses a few possible extensions and Section 7 concludes.

\section{The Structure of the Economy}

Consider an artificial economy populated by a large mass (normalised to unity) of identical individuals. Every individual acts as both a consumer and a producer of a single, perishable commodity. Time is discrete, indexed by $t$ and measured from zero to infinity. Each agent is assumed to be infinitely lived and there is no population growth. Every period an agent carries a stock of intangible - previously accumulated - human or 'efficiency' capital, denoted $h_{t}$, which represents the agent's skill, ability and expertise in producing consumable output. The agent begins her lifetime with an initial endowment of human capital equal to $h_{0}>0$. In addition, I assume the presence of a government whose activities involve the issuing and printing of the economy's medium of exchange, henceforth called 'money', the provision of lump-sum income transfers (in monetary terms) to the private sector and the provision of public goods and services. Concerning the timing of events, I employ the widely used assumption that all uncertainty relating to current events is resolved at the beginning of each period, prior to an agent's formation of optimal decisions.

\subsection{The Private Sector}

Each period, an individual is endowed with one unit of labour and one unit of potential leisure time. The unit of labour is supplied inelastically, and is combined with the agent's human capital so as to produce $y_{t}$ units of output according to ${ }^{5}$

$$
y_{t}=A h_{t},
$$

where $A>0$ is a technological parameter.

\footnotetext{
5 This is an innocuous assumption for the model's implications and employed here simply to save on notation. Introducing elastic labour supply would not change any of the model's results qualitatively because the solution for labour would be stationary, independent of current realisations of the random shock, and with qualitatively identical response to volatility, compared to the optimal time spent on human capital formation (see Footnote 11). Alternatively, we may argue that goods production utilizes effective labour $\left(h_{t}\right)$ whose formation depends on raw time $\left(e_{t}\right)$, the previous level of effective labour and public spending according to the technology in equation (2).
} 
The agent accumulates capital by combining units of time or effort, denoted $e_{t}$, her previously accumulated stock of capital and the provision of public goods and services, denoted $g_{t}$, according to

$$
h_{t+1}=\Psi\left(e_{t} h_{t}\right)^{\psi} g_{t}^{1-\psi}, \quad \psi \in(0,1],
$$

where $\Psi>0$ is a constant. Notice that the limiting scenario of $\psi=1$ corresponds to the technology brought forward by Lucas (1988), in which public goods/services do not contribute to the accumulation of human capital.

The presence of $e_{t}$ captures all the activities that an individual undertakes to promote the formation of human capital and, therefore, productivity. These activities may include formal education, training, research, learning and adoption of new technologies, updating with respect to advanced production techniques etc. The contribution of the public sector, signified by the presence of the variable $g_{t}$, can be explained in terms of the beneficial aspects from the provision of such goods and services as basic infrastructure (e.g., on transportation and telecommunication), public schooling, national health services, the legal framework that establishes property rights and the efficiency of the judicial system, national defence etc. - all being important factors in supporting the evolution of human capital and productivity. It should be noted that human capital is assumed to depreciate fully, i.e., the technology in (2) is derived from $h_{t+1}=\Psi\left(e_{t} h_{t}\right)^{\psi} g_{t}^{1-\psi}+(1-\delta) h_{t}$ after setting $\delta=1$. This restriction is used purely for analytical convenience because, in the presence of stochastic elements, closed-form solutions would be impossible with less-than-full depreciation.

Since the agent spends $e_{t}$ of her potential leisure time in activities that augment her human capital, actual leisure time is given by the residual

$$
l_{t}=1-e_{t} .
$$

The actual amount of time devoted to leisure, together with the consumption of privatelyproduced goods, denoted $c_{t}$, contribute to the agent's well-being which is described by an additively separable, lifetime utility function and of the form

$$
U=E_{0} \sum_{t=0}^{\infty} \beta^{t}\left[\ln \left(c_{t}\right)+\xi \ln \left(l_{t}\right)\right]
$$

where $E_{0}$ is the conditional expectations operator. The parameter $\xi>0$ indicates the weight assigned to the utility derived from leisure activities and $\beta \in(0,1)$ is a psychological 
discount factor, related to the rate of time preference $v>0$ according to the inverse relationship $\beta=1 /(1+v)$.

The per-period budget constraint for an individual is given by

$$
c_{t}+\frac{m_{t+1}}{p_{t}}+\frac{b_{t+1}}{p_{t}} \leq y_{t}+\frac{m_{t}}{p_{t}}+\frac{\tau_{t}}{p_{t}}+\frac{i_{t} b_{t}}{p_{t}},
$$

where $m_{t}$ denotes nominal money balances carried from the previous period, $m_{t+1}$ denotes nominal money holdings chosen to be carried forward to next period, $p_{t}$ is the aggregate price level and $\tau_{t}$ is a monetary transfer distributed by the government. In addition, $b_{t}$ denotes privately issued bonds (in nominal terms) and $i_{t}>1$ denotes the gross interest rate on private debt. The variable $b_{t}$ can be either positive or negative depending on whether an agent is a net lender or a net borrower respectively. Aggregation across all agents implies that the total amount of equilibrium debt will be zero.

In order to generate a motive for holding money balances, I emphasise its role as a 'medium of exchange' by imposing the requirement that money is a requisite to purchase consumption goods. This assumption is illustrated by a cash-in-advance constraint of the form

$$
c_{t} \leq \frac{m_{t}}{p_{t}}+\frac{\tau_{t}}{p_{t}}
$$

The private sector's description is completed by assuming that in the initial period, $t=0$, every agent is endowed with an amount of nominal money equal to $m_{0}>0$.

\subsection{The Public Sector}

The government's role in the economy is twofold. On the one hand, the government is entrusted with the legal authorisation of issuing and printing money. On the other hand, it is assigned with the provision of lump-sum nominal transfers as well as the provision of (potentially productive) public goods and services. Although printing money is intrinsically costless, the provision of public goods is not; it requires real resources in order to be financed. For this purpose, the government exploits its advantageous position on issuing money bills so as to generate the required revenues. It achieves this by using part of the increase in money supply with the aim of acquiring real resources which are, subsequently, 
transformed into public goods in a one-to-one basis. This is possible as long as the government satisfies only a part of the private sector's demand for cash via the newly printed money (i.e., by providing a fraction of its seignorage revenues back to the private sector in the form of lump-sum monetary transfers). The remaining part is satisfied in exchange for real resources.

Formally, each period the government prints a quantity of money equal to $\omega_{t}$. Therefore, denoting money supply by $m_{t}^{s}$, its evolution can be written as

$$
m_{t+1}^{s}=m_{t}^{s}+\omega_{t}
$$

I will assume that $\omega_{t}$ is proportional to $m_{t}^{s}$ according to

$$
\omega_{t}=\mu_{t} m_{t}^{s}
$$

where $\mu_{t} \in(0,1)$ denotes the net growth rate for the supply of money. Consequently, we can write (7) as

$$
m_{t+1}^{s}=\left(1+\mu_{t}\right) m_{t}^{s}
$$

The government can use the revenues from money creation so as to provide a stream of public spending equal to

$$
\Gamma_{t}=\frac{m_{t+1}^{s}-m_{t}^{s}}{p_{t}}=\frac{\omega_{t}}{p_{t}} .
$$

A fixed fraction $q \in(0,1)$ of spending takes the form of nominal (cash) transfers distributed to the private sector. That is

$$
\tau_{t}=q p_{t} \Gamma_{t}
$$

However, the remaining fraction $(1-q) \in(0,1)$ takes the form of real resources that contribute to the provision of public goods and services according to ${ }^{6}$

$$
g_{t}=(1-q) \Gamma_{t}
$$

Following others (e.g., Barro and Sala-i-Martin, 1992), I assume that the quantity of public spending is directly proportional to total output so as to ensure the derivation of an equilibrium with ongoing output growth. Hence,

\footnotetext{
${ }^{6}$ Although one would think that a significant fraction of an increase in public spending is financed by bonds, this may actually apply to OECD countries rather than developing countries. Prati and Tressel (2007) support this conjecture by arguing that many developing economies have accumulated such large amounts of debt that has severely restricted their access to world financial markets and their ability to borrow from them.
} 


$$
\Gamma_{t}=\gamma_{t} y_{t}
$$

where $\gamma_{t} \in(0,1)$.

Policy volatility corresponds to volatility in public spending. In the context of this model, this is associated with random changes in the indicator of 'government size', therefore it is captured by the assumption that $\left\{\gamma_{t}\right\}_{t=0}^{\infty}$ is a sequence of identically and independently distributed random variables with constant mean $\bar{\gamma}$ and constant variance $\sigma_{\gamma}^{2}, \forall t$. In terms of intuition, $\gamma_{t}$ may be thought as a type of productivity shock for the public sector's operation technology. ${ }^{7}$ Various aspects that may contribute to this type of volatility are, among other possible, political considerations (e.g., according to the prevailing political situation, the government's priorities may vary), economic considerations (e.g., various aspects of budgetary policy), political instability or even situations that are not under the control of the government, like differences in the overall characteristics (e.g., ability and experience) of public servants and contractors who are assigned with the task of delivering public goods, services, transfers etc. or even natural disasters. ${ }^{8}$

\section{Equilibrium}

The equilibrium of this economy is described by the following

Definition. Given the initial values $h_{0}, m_{0}>0$, the dynamic general equilibrium is a sequence of quantities $\left\{c_{t}, y_{t}, e_{t}, l_{t}, g_{t}, \omega_{t}, \mu_{t}, \gamma_{t}, p_{t}, i_{t}, m_{t+1}, m_{t+1}^{s}, h_{t+1}, b_{t+1}\right\}_{t=0}^{\infty}$ such that:

$$
\begin{aligned}
& \text { (i) Given }\left\{g_{t}, \omega_{t}, \mu_{t}, i_{t}, \gamma_{t}, p_{t}, m_{t+1}^{s}\right\}_{t=0}^{\infty} \text {, the quantities }\left\{c_{t}, e_{t}, l_{t}, m_{t+1}, b_{t+1}, b_{t+1}\right\}_{t=0}^{\infty} \text { solve an } \\
& \text { agent's optimisation problem; } \\
& \text { (ii) The solutions for } e_{t} \text { and } l_{t} \text { are stationary; }
\end{aligned}
$$

\footnotetext{
7 Fatás and Mihov (2005) attribute the incidence of policy volatility to institutional weaknesses. More specifically, they argue that countries in which the parliament is democratically elected, the judiciary branch is independent and power is shared between central and local governments, possess "more checks and balances (that) do not allow the executive to change policy for reasons unrelated to the state of the economy" (Fatás and Mihov, 2005; page 10).

${ }^{8}$ The argument about natural disasters may be valid when such disasters (e.g., fires, earthquakes, floods) affect mainly residential communities and not productive infrastructure. However, if the effect on productivity is significant, policy reaction may actually reduce aggregate volatility despite the fact that it still entails an increase to the volatility of economic policy.
} 
(iii) The goods market clears every period, i.e., $y_{t}=c_{t}+g_{t} \forall t \geq 0$;

(iv) The money market clears every period, i.e., $m_{t}=m_{t}^{s} \forall t \geq 0$;

(v) The private bond market clears every period, i.e., $b_{t}=0 \quad \forall t \geq 0$;

(vi) The government's budget constraint is satisfied every period, i.e., $\Gamma_{t}=\frac{\tau_{t}}{p_{t}}+g_{t}=\frac{m_{t+1}^{s}-m_{t}^{s}}{p_{t}}$ $\forall t \geq 0$

Denote the Lagrange multipliers associated with (2), (5) and (6) by $\zeta_{t}, \lambda_{t}$ and $\theta_{t}$ respectively. The first order conditions for an agent's optimisation problem are given by

$$
\begin{gathered}
\frac{1}{c_{t}}=\lambda_{t}+\theta_{t}, \\
\lambda_{t}=\beta E_{t}\left[\frac{p_{t}}{p_{t+1}}\left(\lambda_{t+1}+\theta_{t+1}\right)\right], \\
\lambda_{t}=\beta E_{t}\left(\frac{p_{t}}{p_{t+1}} \lambda_{t+1} i_{t+1}\right), \\
\frac{\xi}{1-e_{t}}=\zeta_{t} \psi \Psi e_{t}^{\psi-1} b_{t}^{\psi} g_{t}^{1-\psi}, \\
\zeta_{t}=\beta \Psi \psi E_{t}\left(\zeta_{t+1} e_{t+1}^{\psi} b_{t+1}^{\psi-1} g_{t+1}^{1-\psi}\right)+\beta A E_{t}\left(\lambda_{t+1}\right) .
\end{gathered}
$$

The condition in (14) equates the marginal benefit and the marginal cost of additional consumption: the marginal benefit is equal to the marginal utility of consumption while the marginal cost exceeds the shadow value of foregone wealth because of the additional costs of consumption associated with the cash-in-advance requirement. The condition in (15) equates the marginal cost and the marginal benefit of additional holdings of nominal money: the marginal cost relates to the shadow value of wealth while the marginal benefit is derived by the expected discounted utility value of future consumption (made possible through the availability of more cash), appropriately measured in real terms by taking account of expected future inflation. Equation (16) balances the marginal cost and marginal benefit from borrowing/lending. For a borrower, the former corresponds to the discounted utility value (in real terms, after taking account of expected inflation) of future foregone wealth due to debt repayment while the latter corresponds to the shadow value of additional current 
wealth. For a lender, the shadow value of wealth is the marginal cost of bond holdings while the marginal benefit is associated with the discounted, expected increase in wealth (and, therefore, utility from consumption) due to interest repayments, always in real terms after accounting for expected future inflation.

Equation (17) balances the marginal cost and the marginal benefit of spending more time/effort to the accumulation of human capital: the former is associated with the marginal utility cost of foregone leisure and the latter corresponds to the value of the higher stock of available capital. Given the condition in (18), the higher stock of human capital is valuable not only because it increases the discounted expected value of future consumption (resulting from the corresponding increase of future output) but also because it allows by itself a further evolution of the capital stock in the future. The above arguments become apparent if we substitute (2) in (17) and (18) and use (1) to get

$$
\begin{gathered}
\frac{\xi}{1-e_{t}}=\frac{\psi \zeta_{t} h_{t+1}}{e_{t}} \\
\zeta_{t} h_{t+1}=\beta \psi E_{t}\left(\zeta_{t+1} h_{t+2}\right)+\beta E_{t}\left(\lambda_{t+1} y_{t+1}\right) .
\end{gathered}
$$

A result that will facilitate the derivation of analytical solutions is given as

Lemma 1. In equilibrium, the cash-in-advance constraint is binding.

Proof. Suppose that the cash-in-advance constraint does not bind. Given the complementary slackness condition, this implies that $\theta_{t}=0 \quad \forall t \geq 0$. Substituting this in (15) and observing that its left hand side is equal to the left hand side of equation (16), we get $E_{t}\left(\frac{p_{t}}{p_{t+1}} \lambda_{t+1} i_{t+1}\right)=E_{t}\left(\frac{p_{t}}{p_{t+1}} \lambda_{t+1}\right)$. Of course, this cannot be true given that $i_{t+1}>1$ by assumption. Consequently, the multiplier $\theta_{t}$ is strictly positive for every $t$ and the complementary slackness condition requires $c_{t}=\frac{m_{t}}{p_{t}}+\frac{\tau_{t}}{p_{t}}$.

Effectively, Lemma 1 states that - as long as interest-bearing assets can provide the function of real resource transfers intertemporally - agents will never hold money as a store 
of value. Instead, they hold money only to acquire consumption goods - that is, they use cash purely as a medium of exchange.

Given Lemma 1, the money market equilibrium condition, and equations (8), (10) and (11), we can write (6) as ${ }^{9}$

$$
c_{t}=\frac{m_{t}}{p_{t}}\left(1+q \mu_{t}\right)
$$

Substituting (14) in (15) yields

$$
\lambda_{t}=\beta E_{t}\left(\frac{p_{t}}{p_{t+1}} \frac{1}{c_{t+1}}\right) .
$$

Utilising the money market equilibrium condition, we can rewrite (9) as

$$
\frac{m_{t+1}}{p_{t}}=\left(1+\mu_{t}\right) \frac{m_{t}}{p_{t}}
$$

Next, we can simultaneously multiply and divide the left hand side of (23) by $p_{t+1}$, substitute (21) and solve the resulting expression for $\frac{p_{t}}{p_{t+1}}$. Eventually, we get

$$
\frac{p_{t}}{p_{t+1}}=\frac{c_{t+1}}{c_{t}} \frac{1+q \mu_{t}}{1+\mu_{t}} \frac{1}{1+q \mu_{t+1}} .
$$

The above expression can be substituted back in (22). Taking account that all uncertainty regarding variables chosen at period $t$ is resolved after the realisation of the state of nature at the beginning of $t$, this substitution yields

$$
\lambda_{t}=\frac{\beta J_{t}}{c_{t}}
$$

where $J_{t}=\frac{1+q \mu_{t}}{1+\mu_{t}} E_{t}\left(\frac{1}{1+q \mu_{t+1}}\right)$. This result will prove useful when deriving the optimal allocation of time between human capital accumulation and leisure.

\subsection{Policy Volatility and Monetary Randomness}

\footnotetext{
9 The monetary lump-sum transfer $\tau_{t}$, in addition to the predetermined level of money holdings $m_{t}$, is included in the overall nominal resources available for consumption. As a result, the consumption velocity of money appears to deviate from unity. Hodrick et al. (1991) provide a comprehensive analysis of cash-inadvance models with variable (different from unitary) velocity.
} 
In this part I will show how and why policy volatility causes variability in the growth rate of money supply. If we combine equations (8), (10), (13) and (21) together with the money market equilibrium condition, we get

$$
\gamma_{t} y_{t}=\frac{\mu_{t}}{1+q \mu_{t}} c_{t}
$$

The goods market equilibrium condition is given by $c_{t}=y_{t}-g_{t} \cdot{ }^{10} \mathrm{Using}(12)$ and (13) in this condition, substituting the resulting expression for $c_{t}$ back in equation (26) and solving for $\mu_{t}$ results in

$$
\mu_{t}=\frac{\gamma_{t}}{1-\gamma_{t}}=\mathrm{M}\left(\gamma_{t}\right)
$$

where $\mathrm{M}^{\prime}(\cdot)>0, \mathrm{M}^{\prime \prime}(\cdot)>0$.

Equation (27) lays out the characteristic that distinguishes this model from existing theoretical analyses on the nominal volatility - economic growth nexus. Similarly to these analyses, it shows that the money growth rate is stochastic. The major difference, however, stems from the fact that money growth does not follow an independent stochastic process. Instead, having taken account of the role of money supply as an instrument of government policy (in that case, as an instrument of revenue extraction and public finance), money growth relies on the statistical properties governing public spending as these are reflected by the random variable $\gamma_{t}$. More importantly, we can notice from (27) that money growth is a non-linear function of the random policy variable $\gamma_{t}$, contrary to scenarios where public spending is financed by proportional income taxation - scenarios which result in a linear proportionality between the tax rate and the government spending-to-output ratio. The nonlinear relation in the present framework arises because aggregate money demand represents the base on which the public sector relies in order to extract seignorage revenues. Due to its 'medium of exchange' attribute, aggregate money demand is proportional to aggregate consumption. However, the latter is reduced by a rise in government spending as this requires the government to reduce the private sector's disposable income. Therefore, by trying to increase public revenues (so as to finance spending) the public sector inhibits

\footnotetext{
${ }^{10}$ Notice that part of the government's total spending involves transfers back to the private sector. Only the part of resources used for the provision of public goods (productive or not) represents a resource transfer from the private to the public sector.
} 
aggregate consumption which reduces the aggregate monetary base and, thus, erodes the potential revenues that the government can extract via money creation. Later, it will become clear that this non-linearity is an important determinant not only for the effects of policy volatility on growth but also for the implications arising for the relationship between the inflation rate, inflation volatility and economic growth.

\subsection{Optimal Allocation of Time/Effort}

The model's basic structure reveals the importance of privately committed inputs towards human capital accumulation (captured by $e_{t}$ ) for the economy's growth rate. This part of the analysis is devoted to the analytical derivation of the equilibrium value for this variable.

Upon substitution of (26) and (27) in equation (25) we get

$$
\lambda_{t}=\frac{\beta}{y_{t}} E_{t}\left(\frac{1}{1+q \mu_{t+1}}\right) .
$$

Now, we can substitute (28) in (20) and use the law of iterated expectations to get

$$
\zeta_{t} h_{t+1}=\beta \psi E_{t}\left(\zeta_{t+1} h_{t+2}\right)+\beta^{2} Z
$$

where

$$
Z=E_{t}\left(\frac{1}{1+q \mu_{t+2}}\right)=E_{t}\left(\frac{1}{1+q \mu_{t+s}}\right) \forall s \geq 1 .
$$

Notice that this term is constant because the stochastic process of this model (i.e., that of $\left.\left\{\gamma_{t}\right\}_{t=0}^{\infty}\right)$ - to which money growth is related through equation (27)-generates constant mean and constant variance.

The expression in (29) is a stochastic difference equation with solution

$$
\zeta_{t} h_{t+1}=\frac{\beta^{2} Z}{1-\beta \psi} .
$$

The solution in (31) satisfies the transversality condition $\lim _{s \rightarrow \infty} \beta^{s} E_{t}\left(\zeta_{t+s} h_{t+1+s}\right)=0$ and can be verified by direct substitution back in (29).

We can obtain the equilibrium solution for $e_{t}$ after substituting (31) in (19) and rearranging the resulting expression. Eventually, we get

$$
e_{t}=\frac{\psi \beta^{2} Z}{\psi \beta^{2} Z+(1-\beta \psi) \xi}=\bar{e} .
$$


The optimal decision concerning the time/effort allocated to the formation of human capital displays intuitive responses to the model's structural parameters of preferences and technologies. Specifically, an increase in the discount factor $\beta$ (corresponding to a reduction in the rate of time preference $v$ ) and an increase in the relative importance of private inputs in the formation of human capital (i.e., an increase in $\psi$ ) induce individuals to reduce their leisure and spend more time on augmenting their capital stock. The opposite occurs with a higher value for $\xi$, i.e., the weight assigned to the utility derived from leisure. ${ }^{11}$

More important for my analysis is the optimal response of $e_{t}$ to the parameters of the distribution of the policy variable $\gamma_{t}$. Given (27) and (30), this optimal response will be identified through the presence of the term $Z$ in (32). It is of particular importance because this will determine, to a large extent, the effect of policy variability on the trend of output growth. This is an issue to which I now turn.

\section{Policy Volatility and Long-Run Economic Growth}

We can derive the equilibrium growth rate of output by combining equations (1), (2), (12), (13) and (32). Eventually, we get

$$
\frac{y_{t+1}}{y_{t}}=\Psi[A(1-q)]^{1-\psi} \bar{e}^{\psi} \gamma_{t}^{1-\psi} \equiv \Omega\left(\bar{e}, \gamma_{t}\right)
$$

Clearly, $\frac{y_{t+1}}{y_{t}}$ is state-dependent as it varies over time because of the variability in the policy variable $\gamma_{t}$. The long-run rate of output growth can be obtained by taking the mean value of $\frac{y_{t+1}}{y_{t}}$ from (33). In general, there are two distinct channels through which policy volatility impinges on long-run (or trend) output growth. On the one hand, the direct impact of $\gamma_{t}$ on

\footnotetext{
11 To reinforce my claim in Footnote 5, consider a scenario where the structure of the economy includes elastic labour supply, denoted $n_{t}$. Obviously, (1) and (3) change to $y_{t}=A n_{t} h_{t}$ and $l_{t}=1-e_{t}-n_{t}$ respectively. It is straightforward to show that the equilibrium solutions are $n_{t}=\frac{\beta Z(1-\beta \psi)}{\psi \beta^{2} Z+\beta Z(1-\beta \psi)+\xi(1-\beta \psi)}$ and $e_{t}=\frac{\psi \beta^{2} Z}{\psi \beta^{2} Z+\beta Z(1-\beta \psi)+\xi(1-\beta \psi)}$, while the solutions for (27) and (30) still apply. Consequently, it is evident that the inclusion of elastic labour supply will leave all the model's results qualitatively unaffected.
} 
the growth rate is non-linear. On the other hand, policy volatility will affect $\bar{e}$ through its effect on the statistical properties of money supply's rate of change, i.e., $\mu_{t+s}$.

With the purpose of clarifying these ideas, I shall use the following

Theorem. Let $X$ be some random variable generating a constant mean $\bar{x}$ and a constant variance $\sigma^{2}$. Also, let $F(X)$ be some continuous, monotonic function. Then $M e a n[F(\cdot)] \simeq \tilde{F}\left(\sigma^{2}\right)$ such that $\tilde{F}_{\sigma^{2}}(\cdot)>0(<0)$ iff $F_{X X}(\cdot)>0(<0)$.

Proof. Take a second order Taylor series expansion for $F(\cdot)$ around $\bar{x}$ so as to get

$$
F(X) \simeq F(\bar{x})+F_{X}(\bar{x})(X-\bar{x})+\frac{1}{2} F_{X X}(\bar{x})(X-\bar{x})^{2} .
$$

Taking expectations on both sides and using $E(X)=\bar{x}, E(X-\bar{x})^{2}=\sigma^{2}$ yields

$$
\operatorname{Mean}[F(X)] \simeq F(\bar{x})+\frac{1}{2} F_{X X}(\bar{x}) \sigma^{2} \equiv \tilde{F}\left(\sigma^{2}\right) .
$$

Obviously, the sign of the second derivative $F_{X X}(\cdot)$ determines the qualitative effect of $\sigma^{2}$ on $\operatorname{Mean}[F(X)]$.

In terms of intuition, when $F(\cdot)$ is convex (concave) the positive effect from an exogenous shock is more (less) pronounced than the negative effect generated by an exogenous shock of equal magnitude but of opposite direction. Hence, the variance of $X$ has, on average, a positive (negative) effect on the function $F(\cdot)$.

An important result emerging from the analysis so far can be stated as

Proposition 1. The optimal allocation of time/effort towards the accumulation of capital is inversely related to policy volatility.

Proof. Substitute (27) in (30) to get

$$
Z=E_{t}\left[\frac{1-\gamma_{t+s}}{1-(1-q) \gamma_{t+s}}\right] .
$$


The term inside expectations is concave in the random policy variable. Therefore, following appropriate application of the Theorem, we can deduce that $Z \equiv \tilde{z}\left(\sigma_{\gamma}^{2}\right)$ such that $\tilde{z}^{\prime}(\cdot)<0$. Observing (33), we can check that $\bar{e}$ is monotonically increasing in $Z$. Consequently, we conclude that $\bar{e} \equiv \varepsilon\left(\sigma_{\gamma}^{2}\right)$ and $\varepsilon^{\prime}(\cdot)<0$.

Now, we shall identify one of the main results of the paper - i.e., the result concerning the impact of policy volatility on the long-run growth rate of output. We can do this through

Proposition 2. The long-run growth rate is inversely related to policy volatility irrespective on whether public goods are productive or not.

Proof. The growth rate, as obtained in equation (33), is monotonically increasing in $\bar{e}$ and concave in $\gamma_{t}$ (as long as $\psi<1$ ). Applying the results of the Theorem and Proposition 1 we can deduce that

$$
\operatorname{Mean}\left(\frac{y_{t+1}}{y_{t}}\right)=\operatorname{Mean}\left\{\Omega\left[\varepsilon\left(\sigma_{\gamma}^{2}\right), \gamma_{t}\right]\right\} \equiv \tilde{\Omega}\left(\sigma_{\gamma}^{2}\right)
$$

where $\tilde{\Omega}^{\prime}(\cdot)<0$.

As long as $\psi<1$, the available technology allows public goods to be productive since they complement private inputs in the formation of human capital - this being evident by the presence of $\gamma_{t}$ to which the growth rate is concave. This represents one of the channels through which $\sigma_{\gamma}^{2}$ inhibits trend growth. The other channel works through the effect of policy variability on private inputs towards human capital formation, $\bar{e}$, and has already been identified to be negative as well. The growth effect of volatile policy through this term is the most interesting one as it is not direct but works through the impact of the parameters of money supply on optimal investment decisions, due to the fact that money is non-neutral in this economy.

\section{Inflation, its Variance and Long-Run Growth}


This Section is devoted to the understanding of the role of policy volatility as the crucial link of the correlations between the rate of inflation, the variance of the inflation rate and longrun output growth. A first observation comes in the form of

Lemma 2. Policy volatility, $\sigma_{\gamma}^{2}$, generates (i) volatility in money growth, and (ii) higher money growth on average.

Proof. Part (i) of Lemma 2 is obvious after observation of (27) which reveals that money growth is, ultimately, a function of the random variable $\gamma_{t}$. The same equation, combined with the previous Theorem, can be utilised for establishing Part (ii) given that that $\mathrm{M}\left(\gamma_{t}\right)$ is convex.

The idea behind Lemma 2 becomes even more transparent once we consider a specific probability distribution for $\gamma_{t}$ and utilise it to obtain the first and second moments of the probability distribution for $\mu_{t}$. Let us assume, for example, that the distribution for $\gamma_{t}$ satisfies

$$
\operatorname{prob}\left\{\gamma_{t}=\bar{\gamma}-\sigma_{\gamma}\right\}=\operatorname{prob}\left\{\gamma_{t}=\bar{\gamma}+\sigma_{\gamma}\right\}=\frac{1}{2} \forall t \in[0, \infty),
$$

where $\bar{\gamma}>\sigma_{\gamma}, \quad \bar{\gamma}+\sigma_{\gamma}<1, E\left(\gamma_{t}\right)=\bar{\gamma} \quad$ and $\operatorname{Var}\left(\gamma_{t}\right)=\sigma_{\gamma}^{2}$. Denoting $E\left(\mu_{t}\right)=\bar{\mu} \quad$ and $\operatorname{Var}\left(\mu_{t}\right)=\sigma_{\mu}^{2}$, it is straightforward to establish that ${ }^{12}$

$$
\begin{gathered}
\bar{\mu}=\frac{\bar{\gamma}(1-\bar{\gamma})+\sigma_{\gamma}^{2}}{(1-\bar{\gamma})^{2}-\sigma_{\gamma}^{2}}, \\
\sigma_{\mu}^{2}=\frac{\sigma_{\gamma}^{2}}{\left[(1-\bar{\gamma})^{2}-\sigma_{\gamma}^{2}\right]^{2}} .
\end{gathered}
$$

Obviously, $\sigma_{\mu}^{2}>0$ if and only if $\sigma_{\gamma}^{2}>0$ and $\partial \sigma_{\mu}^{2} / \partial \sigma_{\gamma}^{2}>0$. Naturally, nominal volatility emerges because of fluctuations in public spending for which money is the financing instrument. Furthermore, we can see that $\partial \bar{\mu} / \partial \sigma_{\gamma}^{2}>0$ meaning that an increase in policy volatility results in higher money growth on average. These effects determine the sign of the

\footnotetext{
12 The calculations are relegated to the Appendix.
} 
correlation between policy variability and human capital investment decisions by the private sector. On the one hand, by generating variability in money growth, policy volatility stimulates the optimal value for $\bar{e}$. On the other hand, by increasing average money growth, policy volatility impedes $\bar{e}$. Eventually, the latter effect dominates and ultimately determines, to a large extent, the impact of $\sigma_{\gamma}^{2}$ on long-run output growth.

The strong positive correlation between the inflation rate and its variance has been suggested by numerous empirical analyses (Barro, 1995; Judson and Orphanides, 1999; Fischer et al., 2002; Wilson, 2006; Thornton, 2008). This model provides a novel theoretical rationalisation for this empirical fact: it argues that the link between the first and second moments of the stochastic process for money growth derives from volatility in public spending. Of course, one has to remember that, in a growing economy, money growth is just a proxy for inflation, contrary to economies with stationary output in which, along the steady-state equilibrium, money growth and inflation are coincident. Despite this fact, it is possible to show that the implications for the positive correlation between average money growth and its variance carry forward to the correlation between the mean and the variance of the inflation rate, i.e., $\frac{p_{t+1}}{p_{t}}$.

An expression for the actual, equilibrium rate of inflation is given in equation (24). Combining the goods market equilibrium condition together with (12) and (13) we get $c_{t}=\left[1-(1-q) \gamma_{t}\right] y_{y}$. Substituting in (24) and solving for $\frac{p_{t+1}}{p_{t}}$ yields

$$
\frac{p_{t+1}}{p_{t}}=\left(1+\mu_{t}\right) \frac{y_{t}\left[1-(1-q) \gamma_{t}\right]\left(1+q \mu_{t+1}\right)}{y_{t+1}\left[1-(1-q) \gamma_{t+1}\right]\left(1+q \mu_{t}\right)} .
$$

In the absence of stochastic elements, (36) would be reduced to the familiar Fisher-type equation linking real and nominal growth. However, the implications here are richer. To see this, substitute (27) and (33) in (36) to get

$$
\frac{p_{t+1}}{p_{t}}=\left\{\Psi[A(1-q)]^{1-\psi}\left[\varepsilon\left(\sigma_{\gamma}^{2}\right)\right]^{\psi}\right\}^{-1} \frac{\gamma_{t}^{\psi-1}}{\left(1-\gamma_{t+1}\right)} \equiv P\left(\sigma_{\gamma}^{2}, \gamma_{t}, \gamma_{t+1}\right) .
$$

Given the above, we can derive

Lemma 3. Policy volatility, $\sigma_{\gamma}^{2}$, generates volatility in the inflation rate. 
Proof. Evidently, equation (37) reveals that if $\sigma_{\gamma}^{2}=0$, i.e., if $\gamma_{t}=\bar{\gamma} \forall t$, then $\operatorname{Var}\left(\frac{p_{t+1}}{p_{t}}\right)=0$. Therefore,

$$
\operatorname{Var}\left(\frac{p_{t+1}}{p_{t}}\right)=\hat{P}\left(\sigma_{\gamma}^{2}\right)
$$

where $\hat{P}(0)=0$.

Moreover, we can take account of the fact that the policy shocks have non-linear effects to the actual inflation rate to derive

Proposition 3. Both the inflation rate and its variance are positively related to policy volatility.

Proof. From (37) observe that $P(\cdot)$ is convex to realisations of both $\gamma_{t}$ and $\gamma_{t+1}$. Applying the Theorem and taking account of the result in Proposition 1, we conclude that

$$
\operatorname{Mean}\left(\frac{p_{t+1}}{p_{t}}\right)=\tilde{P}\left(\sigma_{\gamma}^{2}\right)
$$

where $\tilde{P}^{\prime}(\cdot)>0$. Given Proposition 1 and Lemma 3, we also conclude that $\hat{P}^{\prime}(\cdot)>0$.

Intuitively, by stimulating money growth and its variance, more volatile policies increase the average inflation rate and the variance of inflation respectively. These effects are actually reinforced by the fact that policy volatility is detrimental to trend growth, thus imposing an additional upward pressure to both inflation and its variance.

Combining Lemma 3 and Proposition 3, we can draw an important conclusion from

Corollary 1. There is a positive correlation between the mean and the variance of the inflation rate, and it results from the incidence of volatility in public spending.

Finally, by blending the results from Propositions 2 and 3, we can make inferences on issues relevant to the inflation-economic growth nexus. These are summarised in 
Corollary 2. The incidence of policy volatility generates a negative correlation between (i) output growth and inflation, and (ii) output growth and inflation volatility.

There is a consensus among existing empirical analyses, relating to the argument that output growth is negatively related to both inflation and its variance (e.g., Grier and Tullock, 1989; Judson and Orphanides, 1999; Grier and Perry, 2000; Fountas and Karanasos, 2007). The previous discussion shows that my model can account for both these empirically observed correlations simultaneously. The main argument is that policy volatility provides the link between these three indicators of macroeconomic performance.

In a related theme, the model is also able to reconcile the observed negative correlation of inflation volatility and growth, with existing neoclassical models in which nominal volatility actually appears to stimulate growth (Dotsey and Sarte, 2000). The argument is that nominal volatility is not harmful for growth per se. Instead, what causes nominal volatility (in this case, policy volatility) is responsible for a detrimental impact on output growth. In order to understand this, let us revisit the expression in $(30)$ - i.e., the one determining the effect of money supply on the private sector's decisions concerning human capital accumulation. Observing the term inside expectations, we can see that it is convex in $\mu_{t+s}$ : this reveals that, had I considered an independent stochastic process for money growth, nominal variability would have had a positive relationship with income growth. Nevertheless, the preceding analysis has already established that nominal volatility emerges solely as a by-product of volatile public spending (Lemmata 2 and 3) which has a negative effect on output growth (Proposition 2) mainly due to its inflationary pressures (Proposition 3). Effectively, inflation volatility is bad for output growth simply because it is inherently linked with higher levels of inflation.

Before turning my attention to the welfare implications of policy volatility, I will briefly examine its repercussions for the interest rate, given that this is determined by macroeconomic variables that respond to policy changes. We can use (24), (25) and (27) in (16) and manipulate algebraically to derive

$$
\frac{1}{\beta}=E_{t}\left[\left(1-\gamma_{t+1}\right) i_{t+1}\right]
$$


Denoting $E\left(i_{t}\right)=\bar{i}$, we can write this expression as $1 / \beta=(1-\bar{\gamma}) \bar{i}+2 \varrho \sigma_{1-\gamma} \sigma_{i}$ or, solving for the average interest rate,

$$
\bar{i}=\frac{(1 / \beta)-2 \varrho \sigma_{1-\gamma} \sigma_{i}}{1-\bar{\gamma}},
$$

where $\varrho$ is the coefficient of correlation and $\sigma_{1-\gamma}, \sigma_{i}$ are the standard deviations of $1-\gamma_{t+1}$ and $i_{t+1}$ respectively. Obviously, $\varrho<0$ (because the term $1 / \beta$ is constant) while the standard deviations are positive if and only policy is volatile (i.e., if $\sigma_{\gamma}^{2}>0$ ). Therefore, we can conclude that the incidence of policy volatility results in a higher interest rate compared to a situation in which economic policy is not volatile.

\subsection{The Welfare Implications of Policy Volatility}

Since policy volatility affects all major real variables in the model economy, it is safe to conjecture that it has significant implications for social welfare. With the purpose of identifying them we can combine previously obtained results together with the lifetime utility function from equation (4).

The aggregate equilibrium condition in the goods market is

$$
c_{t}=y_{t}-g_{t}=\left[1-(1-q) \gamma_{t}\right] A h_{t} .
$$

Using (2), (12), (13), the result from Proposition 1 and substituting recursively yields

$$
c_{t}=A b_{0}\left[1-(1-q) \gamma_{t}\right] \Phi^{t}\left(\prod_{i=0}^{t-1} \gamma_{i}\right)^{1-\psi}
$$

where $\Phi \equiv[A(1-q)]^{1-\psi}\left[\varepsilon\left(\sigma_{\gamma}^{2}\right)\right]^{\psi}$. Next, we can combine (3) with the result from Proposition 1 to derive $l_{t}=1-\varepsilon\left(\sigma_{\gamma}^{2}\right) \equiv L\left(\sigma_{\gamma}^{2}\right)$ such that $L^{\prime}(\cdot)>0$. Substitution of these results in (4) yields

$$
U=E_{0} \sum_{t=0}^{\infty} \beta^{t}\left\{\ln \left(A h_{0}\right)+\ln \left[1-(1-q) \gamma_{t}\right]+t \ln \Phi+(1-\psi) \ln \left(\prod_{i=0}^{t-1} \gamma_{i}\right)+\xi \ln \left[L\left(\sigma_{\gamma}^{2}\right)\right]\right\},
$$

which can be manipulated algebraically to derive

$$
U=\frac{\ln \left(A h_{0}\right)}{1-\beta}+\frac{f_{a}\left(\sigma_{\gamma}^{2}\right)}{1-\beta}+\frac{\beta f_{b}\left(\sigma_{\gamma}^{2}\right)}{(1-\beta)^{2}}+\frac{(1-\psi) \beta f_{c}\left(\sigma_{\gamma}^{2}\right)}{(1-\beta)^{2}}+\frac{\xi f_{d}\left(\sigma_{\gamma}^{2}\right)}{1-\beta},
$$


where $f_{a}\left(\sigma_{\gamma}^{2}\right)=E_{0}\left\{\ln \left[1-(1-q) \gamma_{t}\right]\right\}, f_{b}\left(\sigma_{\gamma}^{2}\right)=\ln \left\{[A(1-q)]^{1-\psi}\left[\varepsilon\left(\sigma_{\gamma}^{2}\right)\right]^{\psi}\right\}, \quad f_{c}\left(\sigma_{\gamma}^{2}\right)=E_{0}\left[\ln \left(\gamma_{i}\right)\right]$

for $i \geq 0$ and $f_{d}\left(\sigma_{\gamma}^{2}\right)=\ln \left[L\left(\sigma_{\gamma}^{2}\right)\right]$ are all constants and related to policy volatility according to previous results.

As it is evident, volatility impinges on social welfare through its presence in the last four terms of equation (40). The first term represents the direct welfare loss incurred by riskaverse individuals in the presence of fluctuations in consumption. The next two terms emphasise the cumulative negative impact of policy volatility on the growth rate of output (and, thus, on the growth rate of consumption as well): it derives from the negative effect of policy volatility on the formation of human capital, which works through both private and public inputs devoted to human capital-promoting activities. The remaining term indicates the impact of variability on leisure: it is a positive impact given that it induces individuals to reduce the time spent on capital formation and focus more on leisure activities which have a direct impact on utility.

Formally, we can identify these effects after some straightforward differentiation of (40). That is,

$$
\frac{\partial U}{\partial \sigma_{\gamma}^{2}}=\frac{f_{a}^{\prime}(\cdot)}{1-\beta}+\frac{\beta f_{b}^{\prime}(\cdot)}{(1-\beta)^{2}}+\frac{(1-\psi) \beta f_{c}^{\prime}(\cdot)}{(1-\beta)^{2}}+\frac{\xi_{d}^{\prime}(\cdot)}{1-\beta} .
$$

A formal analysis of the expression in (41) leads to

Proposition 4. An increase in policy volatility reduces social welfare.

Proof. See the Appendix.

The positive effect of volatility on leisure is weak relative to the negative effect on consumption and growth. Consequently, the presence of volatility proves detrimental to the agents' welfare. The implication from this analysis is straightforward: policy makers (when this is possible) should try and take actions that do not contribute to macroeconomic volatility, otherwise such policies could either hinder the people's well-being or not improve it to the desired extent. 


\section{Some Possible Extensions}

The presentation and analysis of the model in the preceding Sections makes it clear that the specifications for technologies, preferences, stochastic processes and policies are carefully chosen so as to allow analytical solutions through which the analysis benefits from clarity of both the intuition and the mechanisms involved. As always, the model can be enriched with additional and less restrictive assumptions that may broaden its implications. Of course, such additions may undermine the model's tractability in which case the use of numerical simulations and examples may be unavoidable.

In order to illustrate this point, let us return to the model and consider the parameter $q$, i.e., the policy parameter that governs the distribution of seignorage revenues between lumpsum transfers and the provision of public goods/services. What are the implications for the model when this is treated as a variable optimally chosen by the government - i.e., if the government decides on $q$ by maximising the agents' lifetime utility? As long as this choice of $q$ responds to higher volatility, we may get an additional channel through which volatility impinges on economic growth. Generally, we expect different (and opposite) effects to govern the choice of $q$ : on the one hand, it reduces growth by lowering the equilibrium levels for both $e_{t}$ and $g_{t}$ but, on the other hand, it increases the resources available for consumption and, in addition, leads to more leisure activities. Going back to the expression for expected lifetime utility in (40), it is not difficult to check that, even with a simple probability distribution for $\gamma_{t}$ (i.e., the one specified in Section 5), it is almost impossible to obtain the value of $q$ that maximises $U$ analytically. Nevertheless, this can be done numerically. For example, consider a set of values $\beta=0.65, \xi=0.15, \gamma=0.35$ and $\psi=0.8$. It can be checked that the optimal $q^{*}$ responds positively to increasing values of $\sigma_{\gamma}$ ranging from 0.01 (in which case $q^{*} \simeq 0.129$ ) to as high as 0.34 (which leads to $q^{*} \simeq 0.328$ ). Taking account of the negative response of the growth rate on $q$, we may conjecture that this may be another channel through which policy volatility hampers long-run growth.

As argued previously, the workings and applicability of the model can be broadened by relaxing some of the other restrictions as well. Insofar as this can expand our understanding of the issues mentioned and discussed in this paper, it may constitute a fruitful and worth undertaking avenue for future research. 


\section{Conclusion}

The main idea of this paper was to use seignorage (i.e., money creation) as a means of financing volatile public spending within a stochastic, dynamic general equilibrium model of endogenously sustained growth. The resulting volatility in money supply, combined with the effects of money on human capital formation, yielded some interesting and important results concerning macroeconomic performance. First of all, the model predicted a negative correlation between long-run output growth and policy volatility. In addition, given that both the mean and the variance of the inflation rate are elevated by volatility in public spending, the model provided a possible account for the strong positive correlation between inflation and its variability, as well as their negative correlation with output growth. All these results find support from existing empirical studies.

Of notable interest is the mechanism through which volatility in money supply impinges on activities that augment human capital. In existing analyses, the equilibrium growth rate appears to be a convex function of the random monetary variable. As a result, meanpreserving spreads in the distribution of the money supply shock have a positive effect on trend growth - a result which seems to be at odds with existing empirical studies which strongly suggest a negative correlation between output growth and nominal volatility. The convex effect of money supply on activities that promote long-run growth emerges in my analysis as well. However, the key difference is that the statistical properties of money supply are not independent, but driven by the statistical properties of public spending. Effectively, what causes nominal variability also causes higher money growth, and ultimately leads to the negative effect of policy volatility on long-term output growth. Thus, the underlying source of nominal volatility is inversely related with output's rate of change.

\section{Acknowledgements}

I would like to thank two anonymous referees whose comments and suggestions on an earlier draft have given me the opportunity to improve the paper. Any omissions and/or errors are solely my responsibility. 


\section{References}

1. Agbonyitor, A., 1998. Development expenditures and the local financing constraint. World Bank Policy Research working paper no. 1907.

2. Aizenman, J., Marion, N., 1993. Policy uncertainty, persistence and growth. Review of International Economics 1, 145-163.

3. Barro, R.J., 1995. Inflation and growth. NBER working paper no. 5326.

4. Barro, R.J., Sala-i-Martin, X., 1992. Public finance in models of endogenous growth. Review of Economic Studies 59, 645-661.

5. Basu, P., 2001. Reserve ratio, seignorage and growth. Journal of Macroeconomics 23, $397-416$.

6. Brunetti, A., 1998. Policy volatility and economic growth: a comparative, empirical analysis. European Journal of Political Economy 14, 35-52.

7. Click, R.W., 1998. Seignorage in a cross-section of countries. Journal of Money, Credit and Banking 30, 154-171.

8. Dotsey, M., Sarte, P.D., 2000. Inflation uncertainty and growth in a cash-in-advance economy. Journal of Monetary Economics 45, 631-655.

9. Fatás, A., Mihov, I., 2005. Policy volatility, institutions and economic growth. CEPR discussion paper no. 5388.

10. Fischer, S., 1982. Seignorage and the case for national money. Journal of Political Economy 90, 295-313.

11. Fischer, S., Ratna, S., Végh, C., 2002. Modern hyper- and high inflations. Journal of Economic Literature 40, 837-880.

12. Fountas, S., Karanasos, M., 2007. Inflation, output growth, and nominal and real uncertainty: empirical evidence for the G7. Journal of International Money and Finance 26, 229-250.

13. Friedman, M., 1977. Nobel lecture: inflation and unemployment. Journal of Political Economy 85, 451-472.

14. Furceri, D., 2007. Is government expenditure volatility harmful for growth? A crosscountry analysis. Fiscal Studies 28, 103-120. 
15. Grier, K., Perry, M., 2000. The effects of real and nominal uncertainty on inflation and output growth: some GARCH-M evidence. Journal of Applied Econometrics $15,45-58$.

16. Grier, K., Tullock, G., 1989. An empirical analysis of cross-national economic growth, 1951-1980. Journal of Monetary Economics 24, 259-276.

17. Hodrick, R.J., Kocherlakota, N.R., Lucas, D., 1991. The variability of velocity in cash-in-advance models. Journal of Political Economy 99, 358-384.

18. Hopenhayn, H., Muniaguria, M., 1996. Policy variability and economic growth. Review of Economic Studies 63, 611-626.

19. Judson, R., Orphanides, A., 1999. Inflation, volatility and growth. International Finance 2, 117-138.

20. Koreshkova, T.A., 2006. A quantitative analysis of inflation as a tax on the underground economy. Journal of Monetary Economics 53, 773-796.

21. Loayza, N.M., Rancière, R., Servén, L., Ventura, J., 2007. Macroeconomic volatility and welfare in developing countries: an introduction. The World Bank Economic Review 21, 343-357.

22. Lucas, R. Jr., 1988. On the mechanics of economic development. Journal of Monetary Economics 22, 3-42.

23. Poterba, J.M., Rotemberg, J.J., 1990. Inflation and taxation with optimising governments. Journal of Money, Credit and Banking 22, 1-18.

24. Prati, A., Tressel, T., 2007. What is the most effective monetary policy for aidreceiving countries?, in: Ocampo, J.A., Jomo, K.S., Khan, S. (eds.), Policy Matters: Economic and Social Policies to Sustain Equitable Development. Zed Books, pp. 254-271.

25. Thornton, J., 2008. Inflation and inflation uncertainty in Argentina, 1810-2005. Economics Letters 98, 247-252.

26. Varvarigos, D., 2007. Policy variability, productive spending and growth. Economica 74, 299-313.

27. Wilson, B.K., 2006. The link between inflation, inflation uncertainty and output growth: new time series evidence from Japan. Journal of Macroeconomics 28, 609620. 


\section{Appendix}

\section{A-1 Derivation of (34) and (35)}

Given equation (27) and the specified stochastic process, we have

$$
E\left(\mu_{t}\right)=0.5\left[\frac{\bar{\gamma}-\sigma_{\gamma}}{1-\left(\bar{\gamma}-\sigma_{\gamma}\right)}\right]+0.5\left[\frac{\bar{\gamma}+\sigma_{\gamma}}{1-\left(\bar{\gamma}+\sigma_{\gamma}\right)}\right] .
$$

Factorising the above and manipulating algebraically yields

$$
\begin{aligned}
E\left(\mu_{t}\right)= & 0.5 \frac{\left(\bar{\gamma}-\sigma_{\gamma}\right)\left[1-\left(\bar{\gamma}+\sigma_{\gamma}\right)\right]+\left(\bar{\gamma}+\sigma_{\gamma}\right)\left[1-\left(\bar{\gamma}-\sigma_{\gamma}\right)\right]}{\left[1-\left(\bar{\gamma}-\sigma_{\gamma}\right)\right]\left[1-\left(\bar{\gamma}+\sigma_{\gamma}\right)\right]} \\
= & 0.5 \frac{\left.\bar{\gamma}-\sigma_{\gamma}-\left(\bar{\gamma}-\sigma_{\gamma}\right)\left(\bar{\gamma}+\sigma_{\gamma}\right)\right]+\bar{\gamma}+\sigma_{\gamma}-\left(\bar{\gamma}+\sigma_{\gamma}\right)\left(\bar{\gamma}-\sigma_{\gamma}\right)}{\left[(1-\bar{\gamma})-\sigma_{\gamma}\right]\left[(1-\bar{\gamma})+\sigma_{\gamma}\right]} \\
= & 0.5 \frac{2 \bar{\gamma}-2\left(\bar{\gamma}^{2}-\sigma_{\gamma}^{2}\right)}{(1-\bar{\gamma})^{2}-\sigma_{\gamma}^{2}} \\
= & \frac{\bar{\gamma}-\left(\bar{\gamma}^{2}-\sigma_{\gamma}^{2}\right)}{(1-\bar{\gamma})^{2}-\sigma_{\gamma}^{2}} \equiv \bar{\mu},
\end{aligned}
$$

which is equation (34) in the main text.

By definition, the variance of money growth is equal to $E\left(\mu_{t}-\bar{\mu}\right)^{2}$. Using equation (27) and the specified stochastic process we get

$$
\operatorname{Var}\left(\mu_{t}\right)=0.5\left[\frac{\bar{\gamma}-\sigma_{\gamma}}{1-\left(\bar{\gamma}-\sigma_{\gamma}\right)}-\frac{\bar{\gamma}-\left(\bar{\gamma}^{2}-\sigma_{\gamma}^{2}\right)}{(1-\bar{\gamma})^{2}-\sigma_{\gamma}^{2}}\right]^{2}+0.5\left[\frac{\bar{\gamma}+\sigma_{\gamma}}{1-\left(\bar{\gamma}+\sigma_{\gamma}\right)}-\frac{\bar{\gamma}-\left(\bar{\gamma}^{2}-\sigma_{\gamma}^{2}\right)}{(1-\bar{\gamma})^{2}-\sigma_{\gamma}^{2}}\right]^{2} .(
$$

The first term inside brackets can be manipulated to yield 


$$
\begin{aligned}
& \frac{\bar{\gamma}-\sigma_{\gamma}}{1-\left(\bar{\gamma}-\sigma_{\gamma}\right)}-\frac{\bar{\gamma}-\left(\bar{\gamma}^{2}-\sigma_{\gamma}^{2}\right)}{(1-\bar{\gamma})^{2}-\sigma_{\gamma}^{2}}= \\
& \frac{1}{1-\left(\bar{\gamma}-\sigma_{\gamma}\right)}\left[\bar{\gamma}-\sigma_{\gamma}-\frac{\bar{\gamma}-\left(\bar{\gamma}^{2}-\sigma_{\gamma}^{2}\right)}{1-\left(\bar{\gamma}+\sigma_{\gamma}\right)}\right]= \\
& \frac{1}{1-\left(\bar{\gamma}-\sigma_{\gamma}\right)}\left[\frac{\left(\bar{\gamma}-\sigma_{\gamma}\right)\left[1-\left(\bar{\gamma}+\sigma_{\gamma}\right)\right]-\bar{\gamma}+\left(\bar{\gamma}^{2}-\sigma_{\gamma}^{2}\right)}{1-\left(\bar{\gamma}+\sigma_{\gamma}\right)}\right]= \\
& \frac{1}{\left[1-\left(\bar{\gamma}-\sigma_{\gamma}\right)\right]\left[1-\left(\bar{\gamma}+\sigma_{\gamma}\right)\right]}\left[\bar{\gamma}-\sigma_{\gamma}-\left(\bar{\gamma}-\sigma_{\gamma}\right)\left(\bar{\gamma}+\sigma_{\gamma}\right)-\bar{\gamma}+\bar{\gamma}^{2}-\sigma_{\gamma}^{2}\right]= \\
& \frac{1}{\left[(1-\bar{\gamma})+\sigma_{\gamma}\right]\left[(1-\bar{\gamma})-\sigma_{\gamma}\right]}\left[\bar{\gamma}-\sigma_{\gamma}-\left(\bar{\gamma}^{2}-\sigma_{\gamma}^{2}\right)-\bar{\gamma}+\bar{\gamma}^{2}-\sigma_{\gamma}^{2}\right]= \\
& \frac{-\sigma_{\gamma}}{(1-\bar{\gamma})^{2}-\sigma_{\gamma}^{2}} .
\end{aligned}
$$

A similar procedure for the second term inside brackets yields

$$
\begin{aligned}
& \frac{\bar{\gamma}+\sigma_{\gamma}}{1-\left(\bar{\gamma}+\sigma_{\gamma}\right)}-\frac{\bar{\gamma}-\left(\bar{\gamma}^{2}-\sigma_{\gamma}^{2}\right)}{(1-\bar{\gamma})^{2}-\sigma_{\gamma}^{2}}= \\
& \frac{1}{1-\left(\bar{\gamma}+\sigma_{\gamma}\right)}\left[\bar{\gamma}+\sigma_{\gamma}-\frac{\bar{\gamma}-\left(\bar{\gamma}^{2}-\sigma_{\gamma}^{2}\right)}{1-\left(\bar{\gamma}-\sigma_{\gamma}\right)}\right]= \\
& \frac{1}{1-\left(\bar{\gamma}+\sigma_{\gamma}\right)}\left[\frac{\left(\bar{\gamma}+\sigma_{\gamma}\right)\left[1-\left(\bar{\gamma}-\sigma_{\gamma}\right)\right]-\bar{\gamma}+\left(\bar{\gamma}^{2}-\sigma_{\gamma}^{2}\right)}{1-\left(\bar{\gamma}-\sigma_{\gamma}\right)}\right]= \\
& \frac{\left.11-\left(\bar{\gamma}-\sigma_{\gamma}\right)\right]\left[1-\left(\bar{\gamma}+\sigma_{\gamma}\right)\right]}{1}\left[\bar{\gamma}+\sigma_{\gamma}-\left(\bar{\gamma}-\sigma_{\gamma}\right)\left(\bar{\gamma}+\sigma_{\gamma}\right)-\bar{\gamma}+\bar{\gamma}^{2}-\sigma_{\gamma}^{2}\right]= \\
& \frac{1}{\left[(1-\bar{\gamma})+\sigma_{\gamma}\right]\left[(1-\bar{\gamma})-\sigma_{\gamma}\right]}\left[\bar{\gamma}+\sigma_{\gamma}-\left(\bar{\gamma}^{2}-\sigma_{\gamma}^{2}\right)-\bar{\gamma}+\bar{\gamma}^{2}-\sigma_{\gamma}^{2}\right]= \\
& \frac{\sigma_{\gamma}}{(1-\bar{\gamma})^{2}-\sigma_{\gamma}^{2}} .
\end{aligned}
$$

It is a matter of substituting (A1.2) and (A1.3) in (A1.1) to get 


$$
\begin{aligned}
\operatorname{Var}\left(\mu_{t}\right) & =0.5\left[\frac{-\sigma_{\gamma}}{(1-\bar{\gamma})^{2}-\sigma_{\gamma}^{2}}\right]^{2}+0.5\left[\frac{\sigma_{\gamma}}{(1-\bar{\gamma})^{2}-\sigma_{\gamma}^{2}}\right]^{2} \\
& =0.5 \frac{2 \sigma_{\gamma}^{2}}{\left[(1-\bar{\gamma})^{2}-\sigma_{\gamma}^{2}\right]^{2}} \\
& =\frac{\sigma_{\gamma}^{2}}{\left[(1-\bar{\gamma})^{2}-\sigma_{\gamma}^{2}\right]^{2}} \equiv \sigma_{\mu}^{2},
\end{aligned}
$$

which is equation (35) in the main text.

\section{A-2 Proof of Proposition 4}

Observing equation (40), and because $f_{d}\left(\sigma_{\gamma}^{2}\right)$ represents the only term through which volatility has a positive welfare effect, it is evident that it suffices to show that the expression

$$
\frac{\beta \psi}{1-\beta} \ln \left[\varepsilon\left(\sigma_{\gamma}^{2}\right)\right]+\xi \ln \left[L\left(\sigma_{\gamma}^{2}\right)\right],
$$

is decreasing in $\sigma_{\gamma}^{2}$. Taking the derivative of (A2.1), after substituting $L(\cdot)=1-\varepsilon(\cdot)$, we get

$$
\frac{\beta \psi}{(1-\beta) \varepsilon\left(\sigma_{\gamma}^{2}\right)} \frac{\partial \varepsilon\left(\sigma_{\gamma}^{2}\right)}{\partial \sigma_{\gamma}^{2}}-\frac{\xi}{1-\varepsilon\left(\sigma_{\gamma}^{2}\right)} \frac{\partial \varepsilon\left(\sigma_{\gamma}^{2}\right)}{\partial \sigma_{\gamma}^{2}} .
$$

Therefore, we want to show

$$
\frac{\partial \varepsilon\left(\sigma_{\gamma}^{2}\right)}{\partial \sigma_{\nu}^{2}}\left[\frac{\beta \psi}{(1-\beta) \varepsilon(\cdot)}-\frac{\xi}{1-\varepsilon(\cdot)}\right] \leq 0,
$$

or, given that $\varepsilon^{\prime}(\cdot)<0$ (see Proposition 1$)$

$$
\begin{gathered}
\frac{\beta \psi}{(1-\beta) \varepsilon(\cdot)}-\frac{\xi}{1-\varepsilon(\cdot)} \geq 0 \Rightarrow \\
\xi \leq \frac{\beta \psi}{1-\beta} \frac{1-\varepsilon(\cdot)}{\varepsilon(\cdot)} .
\end{gathered}
$$

After substituting (32) in (A2.2), and cancelling out terms, the condition in (A2.2) is reduced to

$$
1 \leq \frac{1-\beta \psi}{1-\beta} \frac{1}{\beta Z},
$$

which holds given that $0<\beta<1,0<\psi \leq 1$ and $0<Z<1$. 
TABLE 1 Government's Share of Real GDP per Capita $(\%$, in 2005 prices)

\begin{tabular}{|l|l|r|r|r|r|}
\hline COUNTRY & SAMPLE & MIN VALUE & MAX VALUE & MEAN & $\begin{array}{l}\text { STANDARD } \\
\text { DEVIATION }\end{array}$ \\
\hline Nigeria & $1950-2007$ & 1.91 & 29.83 & 6.75 & 5.30 \\
\hline Kenya & $1950-2007$ & 2.50 & 14.09 & 8.27 & 3.63 \\
\hline Ethiopia & $1950-2007$ & 6.81 & 28.65 & 13.06 & 5.38 \\
\hline Zimbabwe & $1954-2007$ & 4.56 & 22.12 & 9.52 & 4.78 \\
\hline Zambia & $1955-2007$ & 8.41 & 29.27 & 15.86 & 5.71 \\
\hline Ghana & $1955-2007$ & 9.75 & 36.88 & 19.25 & 5.20 \\
\hline Angola & $1970-2007$ & 25.48 & 61.67 & 48.45 & 10.75 \\
\hline Sudan & $1970-2007$ & 6.41 & 15.28 & 10.23 & 3.21 \\
\hline Botswana & $1960-2007$ & 8.67 & 27.51 & 15.89 & 5.29 \\
\hline Burundi & $1960-2007$ & 7.96 & 46.51 & 25.89 & 7.89 \\
\hline Malawi & $1954-2007$ & 2.54 & 7.81 & 4.99 & 1.37 \\
\hline Burkina Faso & $1959-2007$ & 14.86 & 38.82 & 30.63 & 6.87 \\
\hline
\end{tabular}

Table 1. Government's share of real GDP per capita (\%, in 2005 prices). Data Source: Heston, A., Summers, R., Aten, B., 2009. Penn World Table version 6.3. 